Taken by strum: ukuleles and participatory music-making in Hamilton, Aotearoa/New Zealand

\title{
Matthew Bannister
}

Ukuleles play an important part in contemporary popular culture - from events such as the Bushman World Ukulele Contest, to performers such as Jake Shimabukuro, Israel Kamakawiwo'ole, Amanda Palmer, Stephin Merritt, ukulele groups like the Ukulele Orchestra of Great Britain, and in New Zealand the Wellington International Ukulele Orchestra and the Nukes. They all gain wide audiences through live performances, Youtube videos and conventional music sales, as do ukulele teachers such as Cynthia Lin. There are also ukulele tuition Internet sites such as Ukulele Underground, and ukuleles have become important in schools, via initiatives such as the Play It Strange Music Trust in New Zealand, for example. Moreover, the ukulele is a Pacific instrument, so it is peculiarly appropriate that New Zealand, as a Pacific nation, should be the focus of this essay. Its concern is with the many ukulele groups that exist at the local level, comprising people of all ages and backgrounds who play the instrument for pleasure, education and relaxation.

A good deal has been written about the growing phenomenon of ukulele groups, mostly from the perspective of participants, and understandably coloured by their general enthusiasm. Some common themes include the ease of acquiring and learning the ukulele, its suitability for amateur musicmaking, its enablement of participation, and its suitability for groups in which participants can both sing and play (Greenberg 1992; Thibeault and Evoy 2011; Giebelhausen 2016). Some of these articles refer to Thomas Turino's (2008) theory of musical participation as a model for understanding ukulele practice, and I want to critically apply that model to ukulele groups in contemporary society.

This article is based on an ethnographic survey of ukulele groups on Hamilton, New Zealand/Aotearoa in 2018. These groups are generally composed of adults and fall into a number of types - tutor-led, where the nominal aim is educational, voluntary groups mainly composed of friends or acquaintances that meet regularly (these two kinds of groups usually feature up to a dozen participants), and mega-groups (larger groups generally composed of members from the tutor-led or voluntary groups, meeting most months) for example the Waikato Ukulele Jam, which has been running since 2016 and can attract up to 70 participants. There are also semi-professional groups such as Sylvia's Toaster. My focus is on 
the former, more participatory types of groups. I participate in a number of these groups myself - the Strumbles in particular, which started in 2015 (this is where half of my 14 respondents came from). The group is mostly middle-class Pakeha women in their 40s and 50s. My partner, Aleisha, also teaches ukulele (face-to-face and online) and organises the Waikato Ukulele Jam, which is where the other participants come from. Demographically, the Jam features a majority of retired people, especially Pakeha women. Most participants have some previous experience of playing music or singing. A minority are formally trained. Almost all participants work or participate in situations that involve education or care - most of the Strumbles are teachers; other participants work in health care or are retired and often involved in care-type situations. Indeed, many of the musical events described here take place in schools, hospitals and rest homes.

Like Christopher Small (2011), Turino is interested in music as an activity rather than an object, as "a primary way that people articulate the collective identities that are fundamental to forming and sustaining social groups... through the act of participating together in performance... Music and dance are key to identity formation because they are often public presentations of the deepest feelings and qualities that make a group unique" (2). In applying Pierce's semiotics to music, he claims that "the vast majority of signs operating in music are icons and indices" (6), and that "for those deeply engaged in listening, dancing, or playing music, symbolic word-based thought may be suspended entirely" (16). His point is that musical activity affects primary processes of bodily orientation, rather than working at a verbal level.

However, ukulele groups almost always use written chord and lyric sheets, so clearly wordbased thought is not entirely absent. The broader point is that Turino's research, being based primarily on ethnographies of traditional, implicitly oral, cultures, such as indigenous Shona music of Zimbabwe and Peruvian Aymara music, doesn't always take into account how modernity inflects the meanings of participation. The presence of lyric and chord sheets in ukulele groups points towards questions about sources of repertoire, which Turino takes for granted, and also suggests how ukulele music scenes connect both to other music and other kinds of social scenes (health and education, for example), and finally also lead to questions about leadership, organization, and power. 


\section{Participation and social unity}

For Turino, "Through moving and sounding together in synchrony, people can experience a feeling of oneness with others. The signs of this social intimacy are experienced directly body to body - and thus in the moment are felt to be true" (2-3). This sense of music as social glue was shared by all ukulele group participants interviewed for this article. It could mean the sense of commonality felt within the group, especially when playing, and the pleasure that resulted:

Jacinta (50) - I definitely like being a member of a band that meets regularly... everyone holds similar values, we all sort of love it... We go for a trip down memory lane, you know?... and so you're pinging on your... life's experiences and memories. I love meeting with the group... and watching their uptake of it and their approach to it and the different strengths people bring... the way our voices and our sound has merged over time ... and on those good days... it comes together so incredibly, that's really exciting... People from different backgrounds... and now it's one sound.

Bobbie (43) - It [playing in the group] makes me feel happy, it gives me a rush of happiness... 'cos I do it socially... around other people that have similar ideals.

Edith (63) - I like the idea of singing in a community, like a church, but I don't want to go to church... I'm social, so I like to meet people.

Angelique (69) - It sounded like a wonderful way to expand my social and musical life... I enjoy the age range we have... it keeps me engaged with other generations ... I'm quite happy to just play with whatever's going on.

Sarah (60)- I enjoy all of it... bashing tunes out with a big group... people develop harmonies impromptu, it's joyful... It's a high pressured environment that we work in (a hospital), so ukes just take you to your happy place...

It could also refer to how participants could use the ukulele as a means of social interaction, through participating in multiple groups: 
Heather (62) - There's Aleisha's classes, the Cambridge group on Wednesdays, and we also go to weekend jams in Rotorua , Taupo, Wellington... Everyone is so welcoming.

Edith (63) - ... the social part's very important, you meet similar people at different events.

People play in groups that meet in members' homes, at social or family events, to interact with children or others, either professionally or informally, as performance or as participation:

Kate (48) - If I go where there's children, then I might take it (the ukulele) with me... it adds a kind of happy flavour to an event, generally more children than adults... because children show their excitement more, they're more likely to join in.

Bobbie - I really enjoy teaching and often a reliever turns up and says I've always wanted to learn [ukulele] and I'll just sit them down and teach them ... amazed how quickly they learn it.

Moana (50) - I think it was one of your [the author's] birthday parties, so you had other people coming in as well and jamming and there were different instruments going as well ... all playing together and to me it was like, wow, it was amazing! Being able to participate in things like that... not just being an audience member.

Heather - Without a doubt, when we have our big family group down [at Xmas], and everyone's playing and these wonderful Samoans (in-laws) playing in about 10 parts of harmony and it is magical ...

A recurrent related theme is the idea of vocal harmony as metaphor for social unity:

Bobbie - I've been surprised how easy it is to sing when you play the ukulele... Singing in a group is incredible cos I always want to harmonise... songs where our harmonies are amazing... and the whole song [is] vibrating in the room.

Some older participants took up ukulele as a response to personal tragedy, such as illness or the death or institutionalisation of a partner: 
Pat (78) - Three years ago my husband went into care and I was determined I wasn't going to sit at home and be miserable ... so I thought I might take up music of some sort... I went along and paid my sub and I've never regretted it... our little group (Hamilton Ukulele Group or HUG) has become more like a family, because we know each other so well... When we first got together we'd have to start a song many times because we weren't in sync, but now we never even think of it.

Karl (65) - I got sick... and the nurse saw my uke... and she said ... would you come to our Xmas party at the cancer lodge? and I thought, well, there's only me... and I thought we've got to get together and have a ... group

John (80) - I was lonely!

Karl - Me and another man I worked with ...we've both been through prostate cancer... he loves to sing and was in the Maori harmony chorus and I've actually given him a uke, and we've got together and played a couple of times.

In these latter cases, the group can act as a substitute family for elderly and isolated people. It can also reinforce existing bonds: Alan - "something we can do together as a couple" and this also apples to the author and his partner, Aleisha. Others play with sisters or other family members - e.g. Moana.

Participation can be a way for immigrants to integrate in the community:

Sarah - Being newish to New Zealand ... it meant a lot to me get involved in community activities.

Turino discusses how in western society, sociality has come to mean conversation (29), and some respondents explicitly identified how music can be an alternative: Julia - "it's a way of being in a group, but not having to chit-chat, I kind of like that." Turino also mentions how feelings of social belonging of "same-ness" need to be balanced against the recognition of social difference, and this can be seen in some of the above comments: the idea of "keeping in touch with other generations", and interacting with ill or otherwise marginal identities, for example. So overall, participation promoted a number of types of collective identity or general feelings of belonging. 


\section{Flow}

On a more individual level, Turino describes the feelings that can arise from musical participation in terms of Csikszentmihalyi's "flow" or optimal experience, "a state of heightened concentration, when one is so intent on the activity, that all other thoughts ... disappear and the actor is fully in the present" (4). A feeling of timeless seclusion can develop:

Angelique - Every Saturday afternoon from 4-6 (when the Strumbles group meets)... That is the best experience... The rest of the world does not exist unless there's an emergency, until 6 o' çlock, it's as simple as that.

Terry (72) - Playing songs I like eg "Folsom Prison Blues". The whole Jam experience - I feel like time disappears - it could go on forever.

Sharon (45) - It's one of those things that shuts everything else out... that allows you to relax more deeply, because you're focused on it... you get into a flow.

To maintain this state depends on a balance between skill levels attained and new challenges being attempted. Here the emphasis is on musical participation as a form of mind-body coordination:

Heather - When I started it was a challenge... [it is] good for your brain... hard to play riff patterns and sing.

Alan (62) - The mind gym aspect [co-ordinating singing and playing] - I get a sense of accomplishment by being able to play a song, keep up with others... What I get out of it is... a cognitive thing... I've had some brain injuries ... [I'm] building my brain back to where it was, keeping your mind active.

Sarah signed up to the James Hill online lessons, which teach solo ukulele, picking, synchronous and interlaced playing... "it takes me back to the days of learning music and scales, which is fun for me". 
Of course, this latter remark raises a point about "flow", which is that it doesn't necessarily depend on the presence of a group. However, one of the conditions of flow is immediate feedback, which is present in the group in the form of other participants):

Alan - in Aleisha's class last Monday night... the 12-bar blues ["Alberta Alberta"]. [I got a] tremendous sense of accomplishment... there was picking I could follow... I could do the blues riff in the middle, I could play the whole thing, I got a real buzz, came in the right time, with everybody else.

\section{Contrasts with earlier experiences of music-making}

Turino argues that opportunities for participatory "flow" experiences are lacking in modernity: "Few cosmopolitan North Americans now grow up participating in the same community-bound music and dance styles from infancy. With the array of musical choices available, there is a larger variety in habitual time sense and musical sensibility, and this often makes finding people to sync with more difficult" (19). Participants confirmed these observations: Kate - "It's unusual in our society for people to be participating in music."

A number of participants commented on this lack of participation by reflecting on other experiences of music and especially music tuition from their pasts.

Heather - I've had a whole lifetime of playing serious traditional music... very proper... boring at times...

Some participants had been in a choir previously to joining the group (and some are still in it):

Kate - I was in a singing group with a tutor but I wanted to leave... there was a pressure to perform... (and it was) not fun because she would get upset when people didn't practice enough.

Bobbie - I was dissatisfied with the singing group... (the uke was) a better way for me to sing, I did it for the singing... [I wanted] something that wasn't so perfectionist or performance based... I've learned to be a better singer in the [uke] group. 
Sharon - I'm a lot more relaxed in the Strumbles... in the choir... there's more kind of tension. more kind of performance, competitive attitude... from (some of) the other members. There's some people who can read music and some who can't so socially it doesn't really work. But I learn a lot from [the choir leader].

Moana had a more dispassionate view: "The choir [she sings in] is a lot more formalised... more about developing vocals... you don't have a lot of leeway for doing your own thing, you get put in a part... whereas the uke group is a bit freer... more driven by participants... with the choir there's someone that we pay to tutor us.

Finally, Julia (55) discusses how:

I have started a ukulele club at school, with kids, but there's a bit of interest from teachers as well... There's another teacher... who's had a lot of... experience in the classical world... she was really worried about all the details, but she says she learned from me, 'cos I say "let's just start playing” and it's all okay, even though some of the kids can only play one chord...

Participatory performance's primary goal is to involve the maximum number of people in performing - "actively contributing to the sound and motion of a musical event through dancing, singing, clapping, and playing... when... these activities [are] considered integral to the performance... In fully participatory occasions there are no audience-artist distinctions, only participants and potential participants" (Turino 28).

Sarah: it always amazes me that you can get a... group of people with not so flash voices... but because everyone's singing together it seems to blend out the blemishes.

The primary emphasis is on social interaction; on the process rather than the product: "the quality of the performance is... judged on the level of participation achieved... with little thought as to how the music might sound" (Turino 29). 


\section{Taste and Judgment}

Turino points out that there are always differences in any participatory group, and these can range from matters of taste to differing skill abilities of players. For Turino, the group is the main thing, but not all respondents reported uniformly harmonious group interactions. For example, Heather did not hesitate to pass judgment on a group she was involved in:

I absolutely cannot abide it... a percentage of the group seem to think the only way to play is as loud and as fast as you can, and it just sounds dreadful... they just ruin the songs, songs that really shouldn't be played fast... it's really, really painful to be part of, really ruins it. Almost a competition... a race to the end... it does tend to happen quite a lot in our community group.

Heather is a trained musician, which is one reason for her authoritative tone. The background of the remarks may be that there had recently been a split in her group due to personality clashes, and a splinter group had formed.

John (80), had a problem with spontaneous performances where he didn't have access to the music:

I detest [it]... if someone's just roped me in to fill up the number... I spent an hour with no music. Looking at where my companion's putting his fingers... I assumed it would be organised... a certain gentleman, he had the music... I didn't... I felt embarrassed...

Another way that participants raise some dissent is in terms of judgments about repertoire most commented that they disliked intensely at least some of the songs they performed but did them anyway:

Bobbie - "Blue Bayou" - I can't stand that song, but I get into it when we play it... Bacharach songs - I don't have a connection to them ... but once we're all singing together it can be amazing,

Kate - I don't like "Wild Horses"... I have very strong feelings about whether I like music or not. 
These examples of dissent raise some questions about Turino's participatory model, which I will address presently.

\section{The question of public performance}

For Turino, presentational, not participatory, performance is the format generally associated with live music in modernity - music performed primarily for an audience, with corresponding expectations about the competence of the performers and/or the integrity of the repertoire. Although many accounts of ukulele groups favour the participation model, in practice, most ukulele groups also present performances. Of course, there are intermediary phases between participation and performance: what Turino calls "sequential participation" (48), where a succession of acts will perform, which then form the audience for the other acts. Karaoke is one example. At the Ukulele Jam, which is mostly simultaneous participation (everyone playing together), smaller groups will sometimes do an item, a "party piece":

Sarah - a fair few people... would like the opportunity to... play for people, which is why the jam, having sort of groups that now and then get up and do a party piece... is really nice... and other people in the room are respectful of that.

The party piece is an opportunity to perform in front of a sympathetic audience and thus provides a useful transition space between participation and performance, although some participants had no desire to take it any further:

Terry - I've only played for an audience once (as part of one of Aleisha's classes, performing as a group at a Waikato Ukulele jam). I prefer playing just for fun.

Other emphasized how they enjoyed listening to other groups as well as participating simultaneously: Moana - "I enjoy listening to other people performing, so it's nice to be able to do that."

Performing situations can vary from informal parties to paid concerts in public spaces, and group members have a wide range of responses to these situations. So how do participants feel about live performance, and what kinds of purposes can performance serve for them? 
Most participants were initially nervous of live performance, because they felt that they lacked the skills.

Kate - I prefer just jamming... if I perform I like to feel we're presenting something as high a standard as we can... There can be too much performing, once every 2-3 months at the most... unless it's a party where everyone is playing.

But it's not just a matter of lacking skills - Angelique, an experienced folk musician, feels that performing should not be the focus for ukulele groups:

I've never been particularly good with being on stage and people just watching... but if there's something else going on, then it's easy... At the start of the group I didn't even like photographs being taken, because I felt like... there was expectation. I think there's a difference between performance and having an audience because in jamming sessions, parties... where it's just kind of happening, I can sit and play for hours.... but the moment anyone puts our name on the blackboard...

These feelings were shared by some other seasoned performers:

Bobbie - It's complicated. I really like acting and being the centre of attention... however... overall, no. I tend to get really nervous beforehand... I feel like I don't do a really good job... I find it stressful 'cos I want to it to be perfect, so I'd rather jam.

Many, however, took the attitude that performing was a challenge, but one worth taking up:

Sarah - Performing... it's something to aim for and work to... if people are... given a bit of... time to think about it and practice... "

Jacinta - I do like performing, and I'm getting used to it... again, I have performed over the years... and I do have that desire to get out and show what we can do. But I am really happy not performing too.

Moana - I quite enjoy performing... it gives you a sense of worth... that you can contribute to community activities... I remember... a young person came up to us and she's like "Oh, you're such a cool group, I wish I could belong to you," and that feeling of, yeah we're a cool group... that boosted the ego... you know? 
As popular musical performance is generally associated with youth, there is an implicit discourse here about ageing and performance. One member of the Strumbles reinforced this reading with a feminist interpretation:

Jacinta - I was thinking about the idea of being visible at this time in my life... and how proud I am to stand with a group... to be showing something creative and cool and colourful... in a public space... Sometimes I feel like as a 50-year-old woman, it legitimises my existence (laughs). My daughter and her friends when they saw us... they were quite inspired, I think.

It is worth noting here that the majority of ukulele participants are middle-aged to elderly women and that performance is a way of bringing them collectively into the public sphere and giving them a visibility that they arguably lack.

Live performances were disproportionately represented in both "best" and "worst" experiences of participants. It seems likely that the public nature of performance, and its being centred around specific events, make it more memorable than participatory jamming, although not necessarily more important.

\section{Applications of participation/performance}

As we have already seen, participation and performance serve various purposes for participants - for example, they can empower particular types of marginal identities. Relatedly, they can also be used in education and social work. There were strong associations between ukuleles and institutional spaces, such as schools, hospitals and rest homes. This phenomenon represents an extension of Turino, to the degree that it shows how ukulele participation/performance can serve different purposes for different people and situations it's not simply an end in itself.

Edith, who works for Literacy Waikato, says that performing music live in her work was "to model behaviour to students... if they're doing things that are uncomfortable for them, like performing. The manager asked us to do an item in front of students... something freaky... to show them [that they could do it too]." Julia has started teaching ukulele at her school, seven years and up, at lunchtimes. Kate and Bobbie, who work in early childhood education, both 
use ukuleles in their jobs. Pat - who is retired, takes her ukulele when she visits her partner in a rest home and performs for staff and patients:

But I do go over to Morrinsville, where Dave is [her husband in dementia unit] and I do it on my own, and the others in the group are amazed... "Oh, don't know if we could do that." But now Karl and Jane and Barbara go over and we play [at the dementia unit]... The residents sing and the staff, we sing all the old songs.

Aleisha would also take her ukulele when visiting her mother (who was in dementia care), noting that since her mother could no longer converse, singing was the best means of communication left to them.

Karl: Going to the rest homes does give me a lot of pleasure. One of the guys there is very, very deaf... and he always comes up to me and says [very slurred] "I can't hear" and every time we play he... shakes my hand and says [slurred] "I could hear that" and [I think] he feels the vibrations in his body... he imitates strumming the ukulele, like "air-uke-ing".

Another use of ukuleles is in a ritual context, for example, staff farewells - at least two participants have written songs to farewell staff members and played them at leaving functions. Kate - "When a staff member leaves... I'll make up a song for them... and get the other teachers to sing. It's a present I can give them." Kate's songs are based on existing songs e.g. "It's a Small World" with new lyrics. However, Sarah noted that this use of the uke was not unproblematic:

It's started to become a bit of an expectation where if really lovely members of staff leave, we actually write them a song... That's a bit of a tricky one, 'cos people where you've not written them a song they start to think “Ooh, I'm not quite as popular as I thought."

\section{Discussion}

Most accounts of ukulele groups define them as primarily participatory, but most ukulele groups in this study have performed in public. Turino claims that participatory music tends 
towards "short, open, redundantly repeated forms" (59) but ukulele repertoire is typically popular songs, which tend towards the "closed scripted forms" (59) that Turino describes as typical of presentational music - i.e. popular songs have fairly fixed structures with verses, choruses, middle eights, and of course, lyrics. Connectedly, performances of these songs tend to be reasonably organised, with clear beginnings and endings, not the "feathered" (59) beginnings and endings Turino hears in participatory music. Finally, Turino contrasts the participatory approach which treats pieces of music as a raw material for group interaction against a presentational emphasis on the music as "set", i.e. autonomous, performed in basically the same way each time (although this does not exclude the possibility of some solo improvisation). So Turino's comments on how performance modes affect musical form do not always apply to ukulele groups.

Ukulele groups mix performance modes, then, and this is not even entirely dependent on context - even in a jam, or informal, private session, a group will tend to play discrete, complete songs, although of course breakdowns and in-between-song noodling are more likely to occur. One reason for this tendency to play complete songs is the presence of scores.

Notably Turino does not discuss scores or their place in performance. The presumption is that they are absent in participatory music. Presentational music tends to be more "scripted", although this doesn't mean scores will be present - rock and classical musicians may both follow a script to some degree, but in the former case it is memory and in the latter it is paper. In ukulele groups, to be more precise, what players usually have is not a notated score but a lyric and chord chart. This has a number of implications for Turino's theory. In popular music, the words are quite important - and while no one would pretend that song lyrics are always deeply meaningful, it is clear that "symbolic word-based thought" is not entirely absent either, as Turino suggests elsewhere. And ukulele playing and popular music in general are as much about singing as playing.

The second point about scores is that they point towards the question - where does repertoire come from? Turino's case studies of traditional music cultures tend to treat repertoire as a given - it just proceeds naturally out of the lifestyle and culture of the people that play it. Turino does discuss one "modern" example of participatory music - contra dance (dances based around old-time music) in contemporary US, but this seems different in some ways to his other examples - while one could be an amateur or beginner dancer in such a scene, one 
could not be a beginner musician, as the dancers depend in many respects on the musicians' expertise (choosing apt repertoire, for example). Or to put it another way, the musicians are performing to some degree, and the dancers are the audience, so it's not just participation.

Because Turino's model is based on traditional cultures, it tends to overlook the role of mediation in modern ukulele culture - most respondents named the Internet and especially YouTube as important repertoire sources. Arguably, the present ukulele phenomenon came about at least partly through YouTube. Sharon: "Maybe it's that kind of YouTube thing in which people who are not famous can get together with their friend and make a video and get a lot of likes, so you can get your five minutes of fame."

The Internet presents opportunities for participatory culture (Jenkins) and there is a continuity between ukulele participation of Turino's type and mediated participation. It doesn't necessarily follow that it's the same thing, however. Granted, many ukulele groups encourage members to contribute repertoire, but members vary in their ability to edit their material so it is easily performable. This could include considerations such as the key of the song (ukuleles are easy to play in only a few keys; keys often need to be changed to suit the pitch of voices, especially songs originally sung by men, as most ukulele groups feature a lot of women); the adequacy of the notation (internet sources vary widely in their accuracy and reliability); and the need to produce compact scores (hard to turn pages when you're playing a ukulele!) etc. An event like the Waikato Ukulele Jam requires considerable facilitation (someone has to organise a venue, put together a document containing all the songs which can be projected and so on). Also, ukulele jams are public events and thus attract the interest of copyright collectors such as APRA in NZ. Indeed, much ukulele music on the Internet is in breach of copyright, as is the act of reproducing it in any form. So, hierarchies of various kinds are a consideration with ukulele groups. Turino tends to downplay conflict and hierarchy in participation: "Participatory performance does not fit in well with the... capitalist-cosmopolitan formation, where competition and hierarchy are prominent" (35). Moreover, most participants in our survey thought that a group should have a leader, and it is clear from the foregoing discussion that a good deal of organisation is necessary for groups to work well. We also saw how ukuleles feature in different social contexts, in schools and rest homes, and as part of social rituals. These situations can have political implications whether or not you write a workmate a song; whether performers are actually doing "work" 
and perhaps deserve to be paid. And there is also the question of playing at political events. Finally, groups sometimes have disputes and break apart, as with Heather's group.

\section{Conclusion}

In setting up musical participation as an ideal, Turino tends to ascribe a lot of autonomy to the musical scenes he describes, but although ukulele groups do provide a kind of alternative place and time for participants, they are still connected to the rest of the social world, and also the musical world. The key sign of that connection is the score or script. Whether a physical object or a memorised script, it reminds us that ukulele groups are always a part of music as a whole - that repertoire does not appear from nowhere but is the result not only of choices made by individuals in the group, thus introducing issues of taste, judgment and expertise, but also of the popular music industry, of capitalism and connected issues of power, from copyright to matters like group leadership and organisation. 


\section{References}

Giebelhausen, Robin (2016). So, You're Thinking About Starting a Ukulele Program? General Music Today 29(3).

Greenberg, M. (1992). The ukulele in your classroom. Music Educators Journal 79(3), 4348.

Jenkins, Henry (2008). Convergence culture: where old and new media collide.

New York: New York University Press.

Small, Christopher. (2011). Musicking: The Meanings of Performing and Listening.

Middletown: Wesleyan University Press.

Thibeault, M. D. (2015). Music education for all through participatory ensembles. Music Educators Journal, 102(2), 54-61.

Thibeault, M. D., Evoy, J. (2011). Building your own musical community: How YouTube, Miley Cyrus, and the ukulele can create a new kind of ensemble. General Music Today, 24(3), 44-52.

Turino, T. (2008). Music as social life: The politics of participation. Chicago, IL: University of Chicago Press. 